\title{
A STUDY ON THE PROPERTIES OF SURFACE - ACTIVE FLUIDS USED IN BURNISHING AND SHOT PEENING PROCESSES
}

\author{
Kazimierz Zaleski' \\ Department of Mechanical Engineering, Lublin University of Technology, 36 Nadbystrzycka Str., 20-618 \\ Lublin, Poland, e-mail:k.zaleski@pollub.pl
}

Received: 2016.05 .06 Accepted: 2016.07.04 Published: 2016.09.01

\begin{abstract}
A method is presented for the study of surface-active properties of a fluids, in burnishing and shot peening processes used, which consists in comparing mean plastic strains of thin metal foil subjected to tensile tests in the examined fluid and in air. As a surface-active additive to the fluid (mineral oil), methyl polymethacrylate solution was used. It was found that the surfactant activity coefficient depended on the type of examined fluid as well as on the thickness of the foil being stretched. Results of analyses of the surface-active properties of a fluid can be compared only when metal foils of equal thickness made from one specific material are used. It can be supposed that the introduction of methyl polymethacrylate solution as an additive to the metalworking fluid will have a beneficial effect on the course and the results of burnishing and shot peening of metals.
\end{abstract}

Keywords: burnishing, shot peening, polymer solutions, methyl polymethacrylate, metalworking fluids, surface-active properties.

\section{INTRODUCTION}

Burnishing and shot peening are metal working processes designed to enhance the surface properties of a variety of machine elements. The application of burnishing and shot peening leads to reduced surface roughness, higher hardness of the surface layer, and the formation of compressive residual stresses [7, 13]. Residual stresses are connected with the density of defects in the crystal structure of the surface layer of a metal. The results of comparative studies on the distribution of residual stresses and positron annihilation suggest that the concentration of defects in the crystalline structure of the surface layer of the shot peened objects evolves [18].

The changes in the surface layer properties caused by burnishing and shot peening have a positive effect on the operational life of produced elements, particularly on their higher fatigue life [16]. Burnishing, especially its type called brushing, can be used to remove burrs which remain after the machining and shaping of workpiece edges [9].

Burnishing and shot peening processes can be run either without the use of cutting fluids (dry processes) or with the use of cutting fluids. Cutting fluids are used in the burnishing and shot peening for reducing friction between the tool and workpiece, and for exerting a surface - active impact on the burnished material $[4,5]$. However, the use of cutting fluids leads to higher production costs and is undesired from an environmental points of view. A compromise solution is to use a minimum quantity lubrication (MQL) $[8,12]$. Minimum quantity lubrication can be applied with the use of surface - active additives, for instance polymer solutions $[5,10]$.

Surface-active agents used as components of fluids applied in metalworking are classified as EP (Extreme Pressure) additives and as polar additives [3]. EP-type additives react chemically with the metal being machined, forming on the surfaces of the machined object and the machin- 
ing tool thin layers of products acting as a permanent lubricating film. The efficiency of the action of EP-type additives can be assessed using a fourball testing machine $[2,6]$.

Polar additives act on the machined object by adsorbing particles of a metalworking fluid on the object's surface, which facilitates plastic deformation and decreases the strength of the machined material. Reduction of the shear strength of the material being cut is listed as one of the three main goals, beside cooling and lubricating, of using metalworking fluids [4]. Changes in the properties of the machined material caused by the surface-active action of metalworking fluids are connected with the Rebinder effect $[1,11]$. A distinction is made between the external and the internal character of the Rebinder effect. The external effect consists in surface interaction between metal and medium, while the internal effect is related to adsorption of surface-active substances onto the inner surfaces of microcracks formed during the process of metal deformation.

Polar-type surface-active additives facilitate the metalworking process as well as having a beneficial effect on the condition of the surface layer and the operational life of the machined elements. These additives cause an increase in blade life of cutting tools and also influence the shape of the chips formed during machining. Introduction of surface-active additives to the metalworking fluid in the shot peening process increases degree of strain hardening of the machined objects surface layer [14].

The surface activity of metalworking fluids can be measured using a method developed by the author, which consists in comparing deformations of thin metal foils stretched in the studied fluid and in air [15]. The aim of the present research was to estimate the influence of the thickness of a metal foil on the results of surface-activity measurements of a fluid to which methyl polymethacrylate solution was added.

\section{MATERIALS AND METHODS}

The study was performed on samples of the thin metal foil of varying thickness. The samples were stretched in fluid containing surface - active additives; in fluid without these additives, and in air (dry process).

Thin metal foils were prepared by the grinding using a special instrument [17]. A schematic design of the instrument for thin metal foil grinding is shown in Figure 1. A grinded foil (1) is mounted on the body of the instrument (6). One end of the foil (1) is mounted in a permanent holder (5), while the other end is mounted in a sliding holder (2). The sliding holder is connected by a connecting link (3) with a clamping mechanism (4) which compensates for the elongation of the foil during grinding and enables formation of a constant tension force in the metal foil.

The body of the instrument (6) is mounted on the work arbor (7) which is mounted between centers of the cylindrical grinder. The grinding process is performed using a disk - type grinding wheel (8). The direction of rotation of the grinding wheel (8) is opposite to that of the instrument's body (6) where the foil (1) is mounted. The body (6) must be attached between the grinding centers such that the cutting force acting on

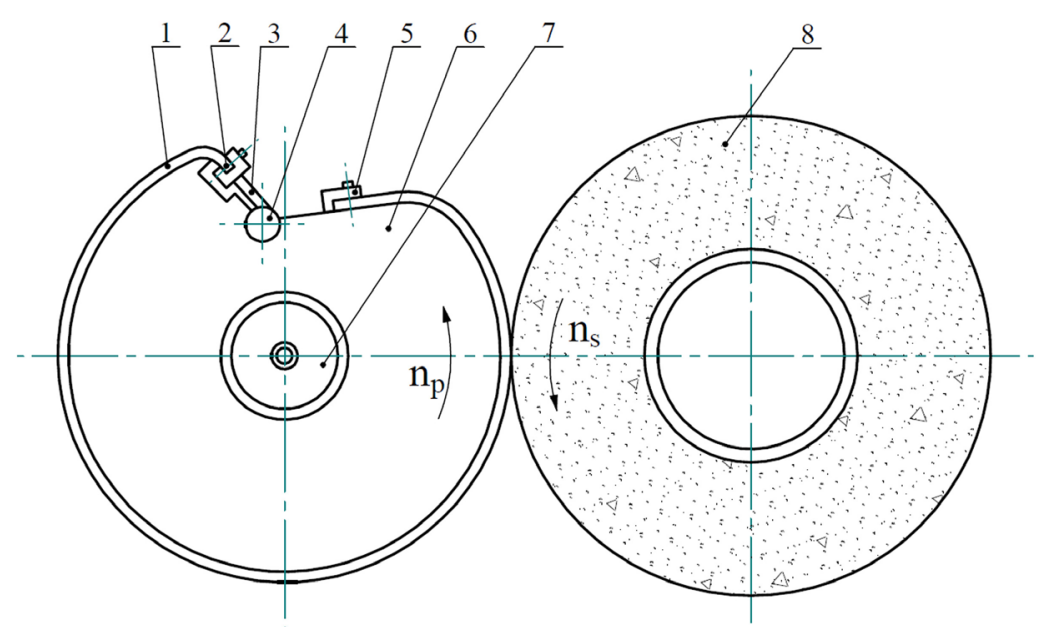

Fig. 1. Scheme of instrument for thin metal foils grinding: 1 - grinded foil, 2 - sliding holder, 3 - connecting link, 4 - clamping mechanism, 5 - permanent holder, 6 - instrument body, 7 - work arbor, 8 - grinding wheel 


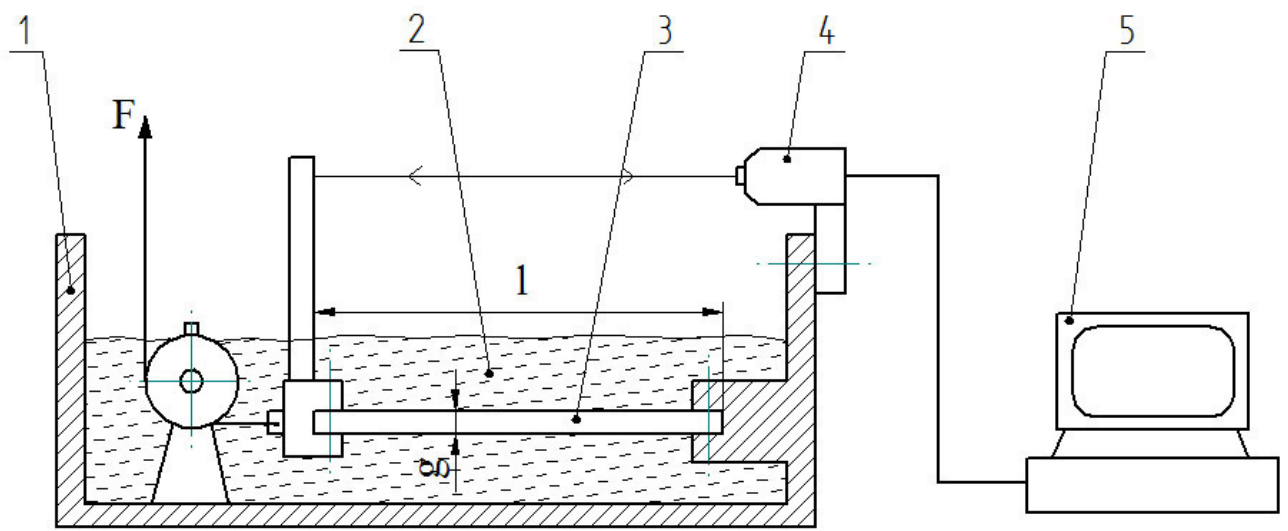

Fig. 2. Scheme of a stand for measurement of surface-active properties of a fluid: 1 - container, 2 - the tested fluid, 3 - metal foil, 4 - sensor, 5 - computer

the foil (1) is oriented from the permanent holder (5) toward the sliding holder (2). As a result, the tension force of the foil is maintained constant during grinding.

Thin metal foil samples have a high reproducibility of shape and dimensions. Therefore, they mast be made with high accuracy. After grinding, the surface roughness of the foil changed in the range $0.42-0.88 \mu \mathrm{m}$. Produced samples should be thoroughly degreased and dried.

Foil specimens for the measurement of deformations during tension were made from normalized C35 steel. The samples were $10 \mathrm{~mm}$ wide and $100 \mathrm{~mm}$ long (the starting measurement length was $50 \mathrm{~mm}$ ). The thickness of the samples was a variable parameter ranging from $0.11 \mathrm{~mm}$ to $0.28 \mathrm{~mm}$.

The studies were conducted on mineral oil with an addition of methyl polymethacrylate solution $(0.5 \%)$. Comminuted methyl polymethacrylate was dissolved in toluene, and the resultant solution was mixed with mineral oil.

Specimens of thickness $g$ were cut out from foil and stretched on the test stand shown in Fig. 2. A container (1) was filled with the examined fluid (2), in which a specimen cut from thin metal foil (3) was subsequently immersed. Before measurement, the specimens were degreased and dried. The tensile force $\mathrm{F}$ of the specimen was gradually increased up to a value slightly below the breaking force. The length of a specimen (1) was measured with a sensor (4) after each increase in force F. Results of the measurements were to send on computer (5). Specimen elongation was measured 30 seconds after increasing the value of the force.

The studies of the effect of tensile force on specimen elongation were conducted for the following media:
- air,

- mineral oil,

- mineral oil with the addition of methyl polymethacrylate solution.

Examples of strain graphs for specimens subjected to tensile tests in air (solid line) and in the mixture of mineral oil and methyl polymethacrylate solution (broken line) are shown in Figure 3. Strains $\varepsilon$ were calculated as quotients, expressed in percent, of the length increment of the stretched foil to its initial length. Tensile stresses $\sigma$ express the relation of force $\mathrm{F}$ to the initial cross-section of the tensile steel specimens.

The curves presented in Figure 3 show total relative strains of the tested specimens, which are sums of their elastic and plastic strains. Mean plastic strains $\varepsilon_{\mathrm{p}}$ can be expressed using the following formula [15]:

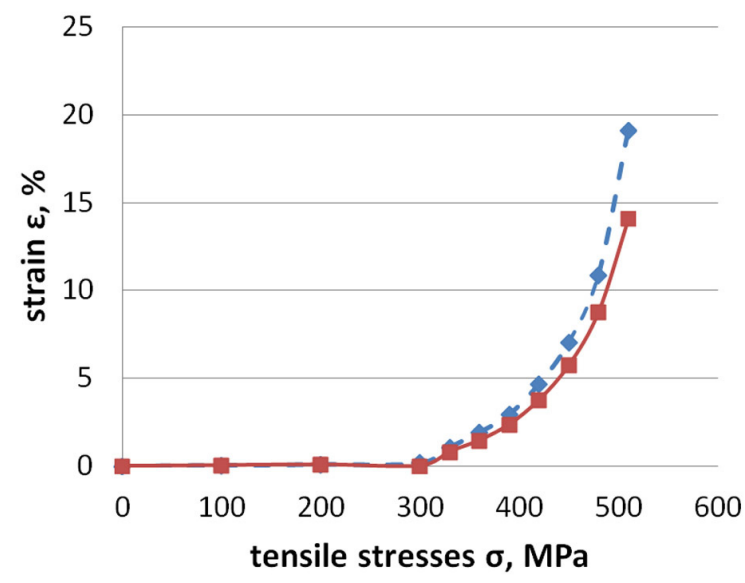

Fig. 3. The stress-strain relation for a specimen stretched in air (solid line) and in mineral oil with an addition of methyl polymethacrylate solution (broken line) 


$$
\varepsilon_{p}=\frac{1}{\sigma_{g}-\sigma_{H}} \int_{\sigma_{H}}^{\sigma_{g}}\left[\varepsilon_{c}(\sigma)-\frac{\sigma}{E}\right] d \sigma
$$

where: $\varepsilon_{c}-$ total strains,

$\sigma-$ tensile stresses,

$\sigma_{g}-$ limit stresses,

$\sigma_{H}-$ elastic limit stresses,

$E$ - Young's modulus.

The value of limit stresses was assumed at a level slightly below breaking stress. To calculate $\varepsilon_{\mathrm{p}}$ from an experimental curve, one can use a rough form of formula (1):

$$
\varepsilon_{p}=\frac{1}{n} \sum_{i=1}^{n}\left(\varepsilon_{c i}-\frac{\sigma_{i}}{E}\right)
$$

where: $\sigma_{i}$-stresses at the $\mathrm{i}$-th point of the $\left(\sigma_{\mathrm{H}}, \sigma_{\mathrm{g}}\right)$ range,

$\varepsilon_{c i}-$ total strains of specimen at stresses $\sigma_{\mathrm{i}}$, $n$ - number of points considered.

The surface-active properties of a fluid where assessed on the basis of the value of the surfactant activity coefficient defined as:

$$
p_{a}=100 \frac{\varepsilon_{p x}-\varepsilon_{p o}}{\varepsilon_{p o}}
$$

where: $\varepsilon_{p x}$ - mean plastic strain of specimens subjected to a tensile test in the studied fluid, $\varepsilon_{p o}-$ mean plastic strain of specimens subjected to a tensile test in air.

\section{RESULTS}

On the basis of experimental curves representing total relative strains as a function of tensile stresses, mean plastic strains $\varepsilon_{\mathrm{p}}$ were determined in accordance with formula (2). Formula (3) was used to calculate the values of the surfactant activity coefficient for mineral oil and for mineral oil with an addition of methyl polymethacrylate solution, using steel specimens of various thickness. The results are shown in Figure 4. Apparent is the effect of the fluid in which the stretched metal foil is immersed on plastic deformations of this foil. The value of the surfactant activity coefficient for mineral oil with an addition of methyl polymethacrylate solution is twice as high as for mineral oil alone.

A significant impact on the value of the surfactant activity coefficient pa is exerted by the thickness of the foil being stretched. A reduction in the thickness of the foil from $0.28 \mathrm{~mm}$ to 0.11 $\mathrm{mm}$ causes an about three-times increase in the value of the coefficient pa. This can be explained by the increase in the ratio of the thickness of the layer whose properties undergo a change under the influence of a surface-active fluid to the thickness of the tensile specimen.

\section{CONCLUSION}

The addition of methyl polymethacrylate solution to the fluid in which a metal foil is being stretched causes an increase in plastic deformations of that foil. The applied study method, which consists in determining mean plastic strains, makes possible the assessment of surfaceactive properties of the fluid. The value of the surfactant activity coefficient pa depends on the medium in which the metal foil is being stretched a)

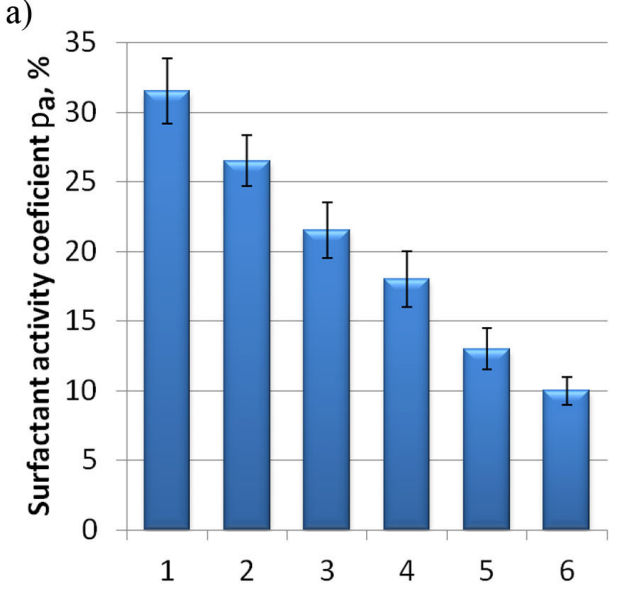

b)

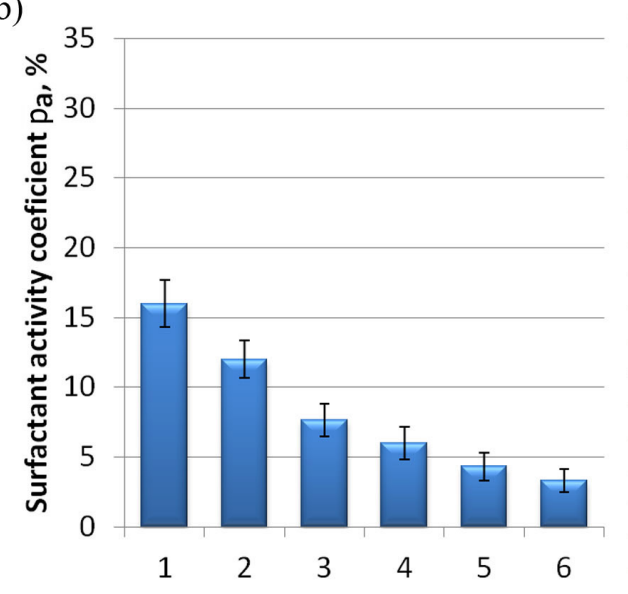

Fig. 4. The effect of metal foil thickness on the surfactant activity coefficient for mineral oil with an addition of methyl polymethacrylate solution (a), and for mineral oil (b): $1-\mathrm{g}=0,11 \mathrm{~mm}, 2-\mathrm{g}=0,14 \mathrm{~mm}$, $3-\mathrm{g}=0,17 \mathrm{~mm}, 4-\mathrm{g}=0,21 \mathrm{~mm}, 5-\mathrm{g}=0,25 \mathrm{~mm}, 6-\mathrm{g}=0,28 \mathrm{~mm}$ 
and on the thickness of this foil. Therefore, using the coefficient pa as an index for the assessment of surface-active properties of a fluid, one has to provide information on the material and the thickness of the foil used in the tests.

Introduction of methyl polymethacrylate solution as a component of a technological fluid used in metalworking should have a beneficial effect on the course of the machining process by facilitating plastic deformations of the machined material.

\section{REFERENCES}

1. Buckley D.H.: Surface effects in adhesion, friction, wear and lubrication. Elsevier Scientific Publishing Company, Amsterdam - Oxford - New York 1981.

2. Cambiella A., Benito J.M., Pazos C., Coca J., Hernandez A., Fernandez J.E.: Formulation of emusifiable cutting fluids and extreme pressure behaviour. Journal of Materials Processing Technology, 184, 2007, 139-145.

3. Dąbrowski J., Firkowski A., Gierzyńska - Dolna M.: Ciecze obróbkowe do skrawania metali. WNT, Warszawa 1988.

4. El Baradie M.A.: Cutting fluids: Part I. Characterization. Journal of Material Processing Technology, 56, 1996, 786-797.

5. Gorohovskij G.A.: Polimery v tehnologii obrabotki metallov. Naukova Dumka, Kiev 1975.

6. Jain V.K., Shukla D.S.: Study of EP activity of water - soluble inorganic metallic salts for aqueous cutting fluids, 193, 1996, 226-234.

7. Kulakowska A., Kukielka L., Kukielka K., Malag L., Patyk R., Bohdal L.: Possibility of steering of products surface layer properties in burnishing rolling process. Applied Mechanics and Materials, 474, 2014, 442-447.
8. Maruda R., Feldshtein E., Legutko S., Krolczyk G.: Research on emulsion mist generation in conditions of minimum quantity Colin lubrication (MQCL). Tehnicki Vjesnik - Technical Gazette, 22, 2015, 1213-1218.

9. Matuszak J., Zaleski K.: Edge states after wire brushing of magnesium alloys. Aircraft Engineering and Aerospace Technology: An International Journal 86/4, 2014, 328-335.

10. Nicholson J.W.: Chemia polimerów. WNT, Warszawa 1996.

11. Pytko S., Pytko P.: Napięcie powierzchniowe a efekt Rebindera. Tribologia, 3, 2007, 143-153.

12. Rakurty C.S., Varela P.I., Balaji A.K.: Effects of targeted Minimum Quantity Fluid (MQF) application on surface integrity. Procedia CIRP, 8, 2013, 462-468.

13. Rodriguez A., Lopez de Lacalle L.N., Celaya A., Lamikiz A., Albizuri J.: Surface improvement of shafts by the deep ball burnishing technique. Surface \& Coatings Technology, 206, 2012, 2817-2824.

14. Shchukin E.D.: The influence of surface - active media on the mechanical properties of materials. Advances in Colloid an Interface Science, 123 (126), 2006, 33-47.

15.Zaleski K.: Stanowisko do badań właściwości powierzchniowo aktywnych cieczy obróbkowych. Przegląd Mechaniczny, 9S, 2005, 55-57.

16. Zaleski K.: The effect of shot peening on the fatigue life of parts made of titanium alloy Ti-6Al4V. Eksploatacja i Niezawodnosc Maintenance and Reliability, 4 (44), 2009, 65-71.

17. Zaleski K.: The manner and device for grinding of thin metal sheet, especially with paramagnetic properties. Polish Patent Number: PL 209068-B1.

18. Zaleski R., Zaleski K., Gorgol M., Wiertel M.: Positron annihilation study of aluminum, titanium, and iron alloys surface after shot peening. Applied Physics A - Materials Science \& Processing, 120, August 2015, 551-559. 